viii

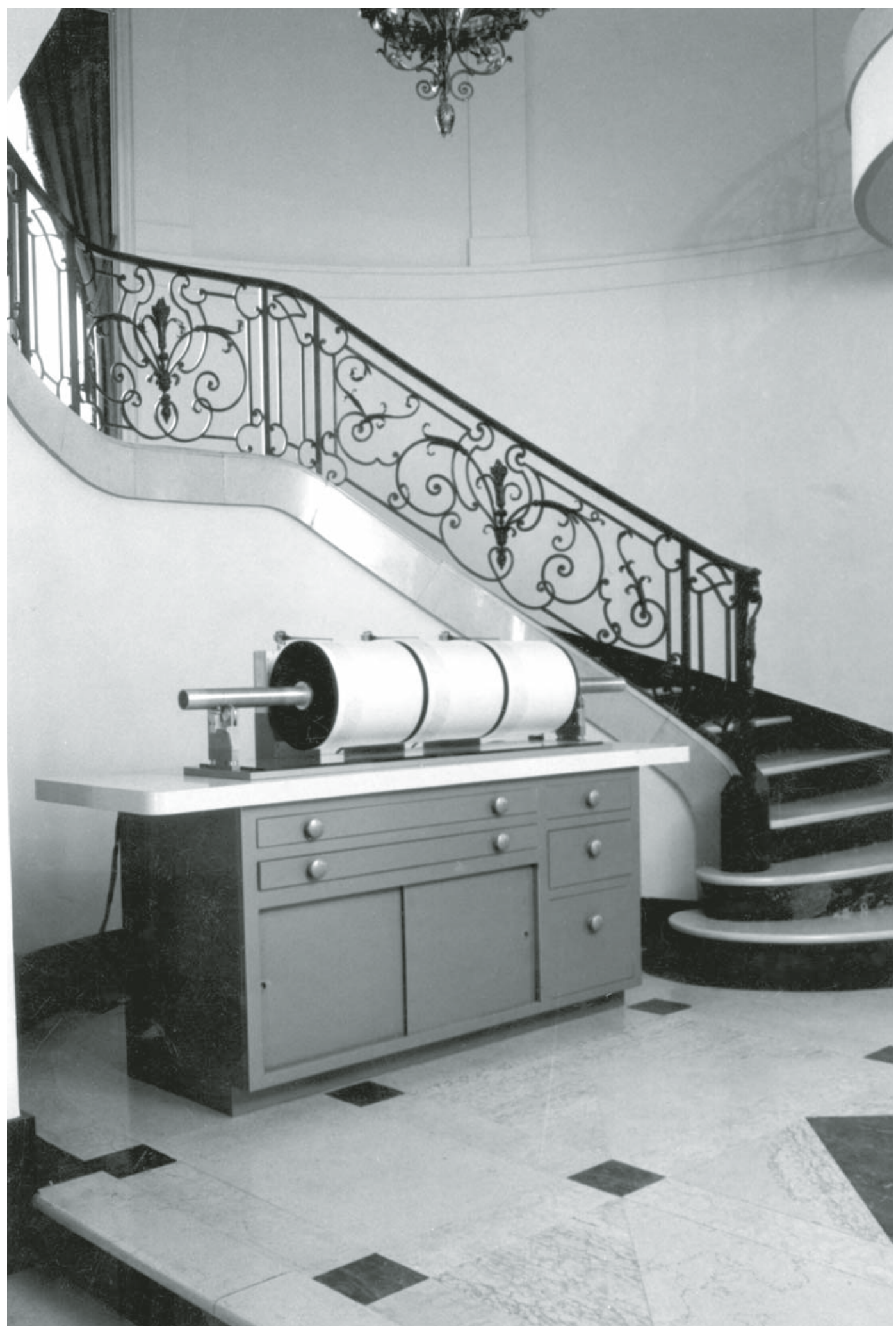

The marble spiral staircase at the Donnelly laboratory in the 1960s. The three drums recorded vertical, northsouth, and east-west motion measured by a Benioff short-period seismometer located in a tunnel some 50 to 100 feet below. The drums made it possible to analyze earthquakes immediately, without waiting for photographic seismograms to be chemically developed. Image courtesy Caltech Archives. 


\title{
Don L. Anderson and the Caltech Seismo Lab
}

\author{
by \\ Many who owe him much
}

The following reminiscences and recollections, scientific and otherwise, were contributed by Don Anderson's scientific colleagues. Incomplete though they are, they give a flavor of the extraordinary range of Don's activities, his influence on Earth science, and the phenomenon that was the Caltech Seismological Laboratory in his time.

Bruce R. Julian

From the mid-1950s until the mid-1970s, the academic staff offices were located in the "upper" (Donnelly) Seismo Lab, a three-story mansion on the south side of the San Rafael Hills, about 200 feet above the "lower" Kresge Lab (or at least it seemed that far when climbing the stairs in the summer). Donnelly coincidentally featured a tunnel, dug into the granite bedrock to provide the original owner with elevator access to his tennis court and putting green, but which was even better as a site for testing and operating seismometers.

The building itself was of course intended as a residence, and was quite unlike most people's idea of a scientific laboratory. An elaborate marble spiral staircase, leading to the second floor, encircled a set of penand-ink seismograph drums beneath a crystal chandelier. Everybody rushed to this staircase whenever there was an earthquake, to find out where it was, and how big, from Prof. Charles Richter. ("It's in southwestern Utah. There was one like it in 1938.") Don Anderson's office adjoined a bathroom, and he used the bathtub to store part of his growing collection of books and reprints. One of the student workplaces ("offices" would be a misnomer) was in an open breezeway, which wasn't too much of a problem when it wasn't raining. A not-tooinaccurate version of the building can be seen in the otherwise forgettable 1974 Hollywood epic Earthquake.

A vacuum-tube Bendix G-15 computer occupied a small room on the first floor. I remember Prof. Frank Press advertising its "two-millisecond add time" to a group of visitors. It was possible to change values in this computer's memory by turning on the room lights, as I learned the hard way, when two mathematical geophysicists (who shall remain nameless) were using it. After that, I just put up with the ambient light.

Sharing this small room was Prof. Stewart Smith's digital seismograph (the academic world's first?), which occupied a seven-foot-high relay rack and recorded three channels from Press-Ewing seismometers located in the tunnel, at one sample per second per channel, onto magnetic tape.

The room also housed the cardpunch machine. If you needed more computing power than the Bendix could provide, or other conveniences like a Fortran (II) compiler, you punched your programs and data onto cards and took them to the main Caltech campus. There a van would pick them up every morning and take them to a big (huge, actually) IBM 709 computer (also vacuum-tube based) in some distant part of Los Angeles and brought them back, along with the printed output, the next morning. Then, if you wanted to avoid an extra day of delay, you had a few minutes to fix bugs and resubmit your cards before the van left again. Accepting the extra day of delay usually was the wiser choice.

The Donnelly laboratory eventually became so full of old boxes of IBM cards that they were a significant economic resource. When the building was sold in the mid-1970s, the graduate students were given permission to sell all the unwanted cards they could collect, and with the proceeds they were able to buy two Hypalon whitewater rafts.

The most memorable part of the lab, in most people's opinions, was the dirt-floored "steam room" opposite Prof. Richter's large seismogram-reading room in the basement. This room was the storage place 


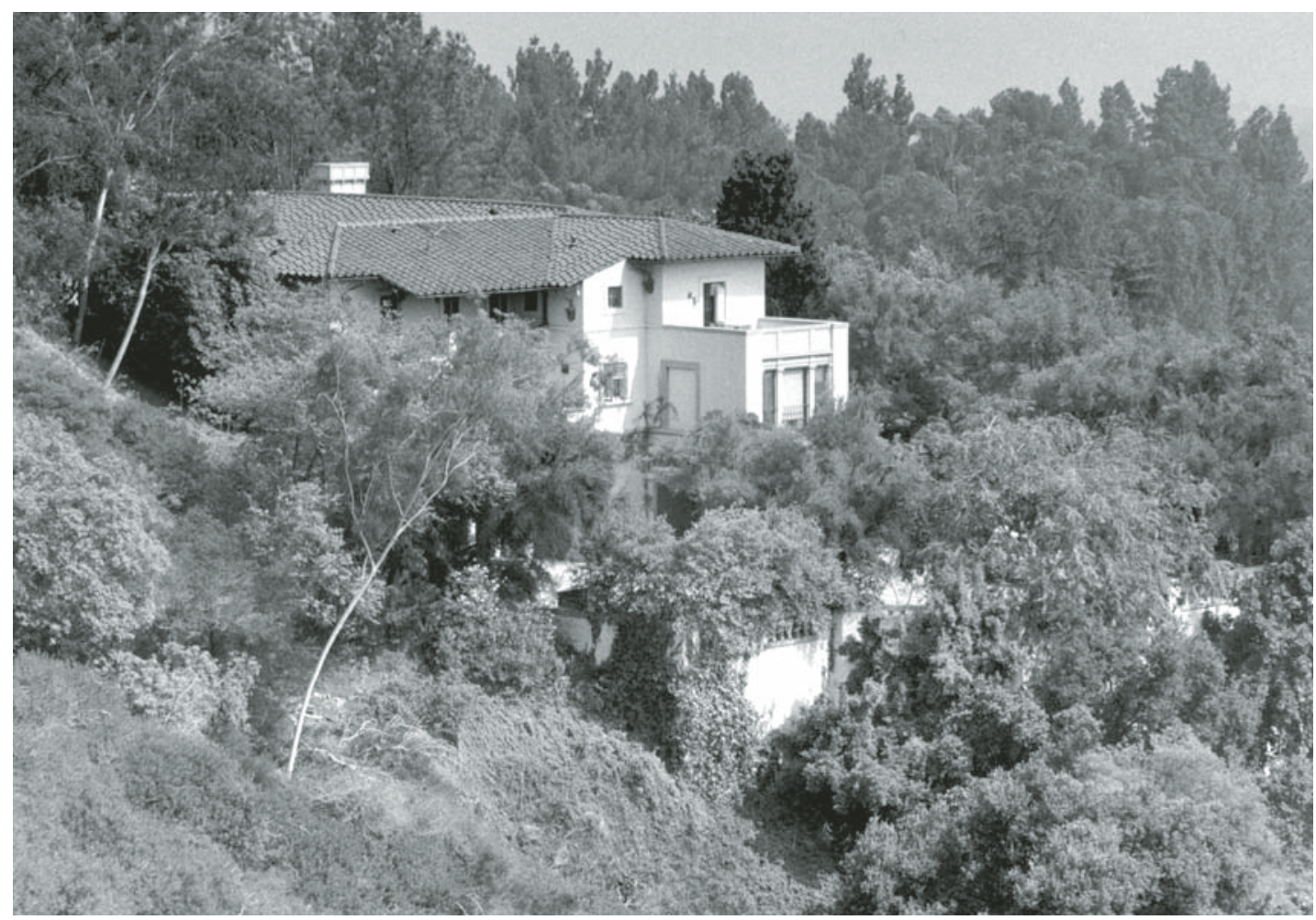

View looking southeast, probably taken in the 1960s, of the Donnelly laboratory in the San Rafael Hills, which housed offices of academic staff and graduate students. The parking area, largely hidden by trees, is immediately in front of the building, and the rock-physics laboratories, also obscured, lie immediately behind it. The entrance to the instrument tunnel is at the base of the hill to the right, out of frame. Image courtesy Caltech Archives.

for historic seismograms, which occupied hundreds of boxes stacked against the walls. It wasn't the room itself that was good, however, or the seismograms. The morning and afternoon coffee breaks had somehow gravitated to the small amount of space left between the boxes. This became a forum for countless discussions of all manner of questions. "What does this error message mean that I keep getting?" "Should that be the group velocity or the phase velocity?" "At what distance do body waves become surface waves?" ... The coffee "room" had never been intended as a discussion place, but I doubt that anyone could have designed one that was more productive.

Bruce R. Julian

Don Anderson and I arrived at Caltech in the fall of 1958 as new graduate students. Don had had some years of experience as a researcher in the Air Force (Cambridge Research Laboratory). In the late 1950s, a number of graduate students had served in the military before beginning their graduate studies. Don had spent his time in active research and, by the time he started graduate school, had published papers and done a significant amount of fieldwork. Most others, like me, had no research experience.

In the Air Force, Don's research involved the study of sea-ice properties, to evaluate its suitability for landing airplanes. He had looked at problems like the seismic flexural waves of ice sheets and the anisotropy of ice, among other topics. He had spent quite a bit of time in Greenland making measurements. An anecdote I recollect from his studies: He ran a seismic survey with a line of seismometers placed along the runway to monitor the ice movement during the takeoffs of the planes. He had asked the pilot to taxi parallel to the seismic line that he had laid on the ice. The pilot, making sure that he was following the line, apparently put the front wheel of the plane right on the line and destroyed every single seismometer Don had planted. Don was disappointed, but, at the same time, he was amazed by the ability of the pilot to taxi with such precision. 
Don's studies on anisotropy led him to investigate the anisotropy in the Earth's upper mantle and to explain the discrepancy between Rayleigh and Love wave dispersions. Some of our joint studies, including ultrasonic laboratory studies, were guided by his knowledge of and interest in seismic anisotropy.

Another episode: Don and Nancy arrived in Pasadena with two young children, Lynn and Lee, and a trailer. For the next two years the trailer was their home. In spite of their limited space, they were very kind to single graduate students, like Fran McMichael and me, and invited us frequently for home-cooked meals. As I look back to my early years at Caltech, I remember Nancy's and Don's kindness. I also appreciated being in a family environment with two wonderful children - they were both cute, and Lynn was a chatterbox while Lee, the younger of the two, hardly said a word.

Both Lynn and Lee were born in Massachusetts. Don used to tell us that the children were named after his favorite towns in eastern Massachusetts. Some years later, when I moved to MIT, I discovered that neither Lynn nor Lee were really great towns. Lynn, however, was adjacent to one of the most beautiful towns in Massachusetts-Marblehead. I am glad that he did not get inspired by Marblehead to name his offspring! Another beautiful town on the shore is Gloucester - that too could have been a disaster as a name, since no one knows how to spell it or pronounce it! Don probably wanted both of his children to have their names start with his middle initial—-"L."

Don was so far ahead of us, his fellow grad students at Caltech, in experience and research that he became a mentor for those of us who came to graduate school directly after receiving our undergraduate degrees. From this, I have benefited throughout my professional life.

M. Nafi Toksöz

Payson, Arizona, sometime in the mid-sixties-The Defense Department had recently installed a large array of seismometers in the Tonto Forest area, for research on detecting and identifying nuclear tests. They had invited a number of seismologists from around the country to visit for its opening, and we were all staying in a local motel that had a bar. In the evening a group of us had gathered at the bar and were seated around a large table, drinking beer and solving deep geophysical problems. There was a small band playing country music, and a number of people were dancing.

One [person] in our group noticed a girl who seemed to be alone and asked her to dance. It turned out she seemed to be alone only because her boyfriend had gone to the men's room. Very shortly thereafter a somewhat drunken cowboy emerged and his friends started kidding him that someone from our group had danced with his girl. He came over to our table, not knowing who the culprit was, but bent on some kind of confrontation. Clearly he wanted to fight someone, but didn't know who, so he settled for going around the table pointing his finger and asking each one of us "Do you think I'm chicken?" Don, who was sitting next to Jack Healy, responded meekly "No," or "Certainly not," just as all of us up to that point had done. Next, the finger pointed at Jack Healy, and there was a pause. Jack gave a long drawn-out "Well, ...." At that point it looked like an explosion was about to happen, but the cowboy's friends dragged him away. Don and I were sharing a room in the motel, and later that night we heard the cowboy pounding on all the doors and hurling insults, apparently hoping that the guilty party, wherever he was, might emerge to do battle. When he came to our door, Don and I were exceedingly quiet, as apparently were all in our party.

Stewart W. Smith

In 1963, two years after I arrived at the Seismo Lab as a graduate student, Don became a newly minted assistant professor. I remember taking a course from him on geophysics that dealt with Earth's structures. The Worldwide Standard Seismic Network and several seismic arrays were now in full operation and the studies of surface and body waves blossomed. Soon the crust and the upper mantle became Don's playgrounds, but quickly he moved beyond traditional seismological research. As a student I was most impressed by Don's seemingly boundary-less studies. He went where the problems led, whether it required him to bone up on mineralogy, petrology, or geochemistry. This attitude and his relentless pursuit - he was usually at the Lab on the weekend - made the most profound impression on me, and served as a model through my whole career. Don's wide-ranging endeavors and numerous successes dealing with the fundamental problems in the crust and mantle are by now legendary. 
Those of us at the Lab in the 1960s during the early development of plate tectonics theories probably all remember how Don's mind operated. He worked on arctic ice during his service. So while we were all learning about transform faults and ridges, Don would tell us how similar structures are formed on the ice sheets. Well, that got translated later to his New Theory of the Earth. This is a book that keeps me awake for hours trying to comprehend, scientifically and philosophically, how whole-Earth geodynamics may work. I often think the Earth needs Don to tell its complex story.

Francis $W u$

Don was among the hardest-working and most productive scientists at the Seismo Lab. In the early 1960s, in rapid succession he produced a number of important papers that gained him a worldwide reputation.

I remember Don's old junky car having constant starting problems. He solved these by parking it heading down-slope in the Seismo Lab's driveway and letting the brake go.

When Frank Press moved to MIT in 1965, Francis Wu, Lane Johnson, and I were put into Don's charge as thesis advisees, and benefitted a great deal from his guidance. His reading of our manuscripts was quick and his comments were numerous and sharp. I almost felt I had to be equally fast and do revisions immediately. The Seismo Lab coffee breaks, which had begun under Frank Press and which Don continued, were a great tradition; we graduate students benefitted greatly from hearing discussions among the faculty and postdocs. Sometimes visiting scientific giants such as Sir Harold Jeffreys or Keith Edward Bullen would join these discussions.

Francis Wu and I once did a 2D ultrasonic model study of a core-scattering problem. When I went to the University of Southern California to start a geophysics program, I continued this research, seeking an analytical solution for the problem. I was very grateful that Don asked his then-Ph.D.-student Paul Richards to work with me. We overcame the mathematical difficulty and completed the analysis, and from Paul I also learned a lot about rigorous analysis.

As the program at USC grew, we frequently hired Seismo Lab graduates (mostly Don's students): Tom Henyey, Charles Sammis, Kei Aki (a Seismo Lab post-doc from 1960 to 1964), and later on Tom Jordan.

In front of his home in Cambria, Don constructed a beautiful rock garden using various large crustal and mantle rock slabs. In the scientific world, he has also constructed a solid framework of seismology and physics of the Earth, on a scale and with thoroughness that few of us can even dream of.

Ta-Liang (Leon) Teng

I got into geophysics through a summer job following my junior year. In 1963, Don Anderson, then a recent Ph.D., hired me to plot theoretical surface-wave dispersion curves on sheets of graph paper the size of a desktop. Each point came from deep within a ream of computer printout and had to be vetted for correctness, because the numerical methods were not infallible (Did the kinetic energy in the wave equal the strain energy? Was the group velocity close to the value given by the slope of the phase velocity?). All had to be plotted precisely by hand, using a pin and magnifying glass. The dispersion curves extended to periods of a few hundred seconds, which had only recently become observable due to advances in instrumentation, and were sensitive to upper-mantle structure. One of the main goals of this work was to establish the reality and nature of the upper-mantle "low-velocity zone," which had been a subject of long-standing controversy.

Don's own Ph.D. topic, elastic wave propagation in anisotropic media, turned out to be useful in the dispersion computations. The first surface-wave computer programs assumed plane-layered media, the extension to spherical shells being a considerable complication. It turned out, though, that making the layers anisotropic could produce useful approximations to the effect of sphericity. For Love waves, in fact, the “approximation" was exact, as I recall.

Plotting dispersion curves soon became tedious, so I eagerly moved on to the second part of my summer assignment, which was to learn to program a computer, hoping to become more useful as a programmer than as a plotter. It worked! Don assigned me to write a program to compute body-wave travel-time curves. Among the things that the surface-wave observations showed were hints of zones of rapid increase in wave speed at depths between 350 and $700 \mathrm{~km}$ in the upper mantle. Don recognized that body waves would be best suited to verifying and investigating these "transition-zone discontinuities" (as they came to be called), but 
that it would be necessary to look at later-arriving waves, because the putative discontinuities would produce multi-branched travel-time curves, and most of the information about structure would be in the later-arriving branches. Applying computers to seismic rays turned out to work brilliantly, producing among other things beautiful pictures of seismic ray paths that clarified the way in which multi-branched travel-time curves were related to details of Earth structure.

High-quality seismic data from nuclear explosions in Nevada were just becoming available, and these were ideally suited to studying crustal and mantle structure, because the signals were large and simple and because the source locations and times were known. Don put me to work taping dozens of these seismograms together into record sections covering large areas of the tables and floor, and poring over them to try to identify later-arrival branches. At the same time, Don put others to work approaching the problem from different directions. Mansour Niazi and Lane Johnson measured the slowness with which $P$ phases from earthquakes crossed the Tonto Forest seismometer array in central Arizona. These data, combined with the nuclear explosion travel times, left no doubt about the reality of the transition-zone discontinuities.

Don also got the Seismo Lab involved in making high-pressure and high-temperature measurements on minerals, to help understand the seismological results. Bob Liebermann's contribution (below) gives details about this major long-term undertaking. Don's greatest contribution to Earth science, in my opinion, was in bringing different disciplines together to work on problems of Earth structure, composition, and dynamics.

A major component of the move to study minerals at high pressure was Tom Ahrens' establishment of a shock-wave facility in the basement of the "lower" (Kresge) Seismo Lab, which also housed shops and the darkrooms where seismograms were recorded onto photographic paper and then developed. The centerpiece of the shock-wave facility was (and still is) a large naval cannon, which was modified to shoot small projectiles into targets at hypersonic speeds. This canon, still on its naval mount, appeared one day in the late 1960s in the Kresge parking lot, where we graduate students were supposed to park. That was surprising enough. However, a few days later when I came to the lab, the breech was buried three or four feet into the asphalt, with the barrel pointed steeply upward. Apparently some neighborhood kids had found the cannon as interesting as I did, climbed over the fence on the weekend, and started turning the various cranks and wheels to see what they did. Unfortunately, the cannon had been un-bolted in preparation for removing it from its mount, and pointing it steeply upward was a BAD IDEA. Fortunately, there were no squashed kids embedded in the asphalt, but I imagine that there were some badly frightened ones in the neighborhood.

Bruce R. Julian

Don's interest in mineral physics grew out of his work on sea-ice elasticity and strength in Greenland for the Air Force in the 1950s. In 1967, in one his first and most significant initiatives at Caltech, he recruited Tom Ahrens from the Poulter Laboratory of the Stanford Research Institute.

In the late 1960s, in a paper with Charlie Sammis and Bob Phinney, Don proposed Brillouin scattering as a new geophysical tool to measure sound velocities in minerals. One outcome of this experimental effort was a paper by Hsi-Ping Liu on the high-temperature elasticity of $\mathrm{MgAl}_{2} \mathrm{O}_{4}$ spinel. In a complimentary initiative to characterize the elastic properties of minerals, Don used his Sloan Fellowship grant to support Hartmut Spetzler in building an ultrasonics laboratory for experiments at high pressures in a gas-medium apparatus. Spetzler had become inspired to do equation-of-state work by Orson Anderson (no relation) while he had been a visiting professor at Caltech.

While waiting for the gas apparatus to be built, Spetzler and Don performed an interesting study on frozen salt-brine mixtures, which has, even today, important implications for partial melting in the low-velocity zone of the upper mantle. Spetzler's ultrasonics experiments reached $0.8 \mathrm{GPa}$ and $800 \mathrm{~K}$ in his doctoral thesis. This research led to important papers on single-crystal and polycrystalline $\mathrm{MgO}$ and single-crystal $\mathrm{NaCl}$ (the latter with Sammis and Rick O'Connell).

In the late 1960s, Don became interested in studies of equations of state and crystal structure from shock-wave experiments. In this work, he collaborated with Hiroo Kanamori and later Geoff Davies. In 1969, he wrote a review paper with Ahrens and Ted Ringwood in the Reviews of Geophysics on this topic. This and other papers explored various mineralogical models for the sharpness of the polymorphic phase boundaries using the relevant solid-solution phase diagrams and applied these models to explain the seismic discontinuities in the transition zone of the Earth's mantle. 
Also in the 1960s, both Orson L. Anderson and Don L. Anderson published papers on the systematic relationship between the bulk modulus and molar volume of minerals. In Orson's case, this led to a proposed "law of corresponding states" while in Don's case to a "seismic equation of state." It also created some confusion in referencing their work, and since O.L. Anderson and D.L. Anderson looked virtually identical in small print, editors allowed authors to spell out their first names when citing their papers.

In the 1970s, Don was fascinated by attenuation and dispersion of elastic waves, both in laboratory experiments and in the Earth, and worked with Hsi-Ping Liu and Bernard Minster on these studies. In a paper with Charlie Sammis, they concluded that something other than temperature and pressure was needed to explain the seismic models of the upper mantle, perhaps partial melting and/or oriented cracks.

Don also recognized the importance of relating sub-microsecond data from shock-wave experiments to the near-equilibrium properties of rocks and minerals under most natural conditions, and conversely, of using static measurements to understand what happens during the passage of shock waves through rocks and minerals. This led to a series of papers with Ed Gaffney and Bernard Minster. With Ed, he was also one of the first to explore the transition from high-spin to low-spin in Fe and implications for the lower mantle. Ed also reminded me of one of Don's favorite expressions: "A clean desk is the sign of a sick mind!"

One of Don's signature traits was his ability to recognize talent in graduate students and postdocs and to enlist them in some of his pet projects, even if they were being supervised or paid by other faculty (as Tom Duffy reminded me, this is also due to the nature of Caltech's system requiring graduate students to work with more than one professor). The most notable examples of this occurred in the 1980s. When Jay Bass was a postdoc in Tom Ahrens' lab, Don developed a collaboration with him that led in 1984 to two important papers in Geophysical Research Letters ${ }^{1,2}$, challenging the prevailing theory/dogma that the composition of the mantle was predominantly peridotitic (or pyrolitic in the nomenclature of Ringwood and Green). They proposed an alternative petrological model, which they termed "piclogite," whose mineralogy was dominated by garnets and pyroxenes, with much less olivine than pyrolite. The debate about which petrological model is valid for the upper and lower mantle continues to this day. Also in the 1980s, as an outgrowth of a term project in Don's course on Physics of the Earth's Interior, Tom Duffy, a graduate student in Tom Ahrens' shock-wave lab, worked with Don on seismic velocities in mantle minerals and published a seminal paper in Journal of Geophysical Research in $1983^{3}$, which remains a standard to this day.

Don regularly taught the course "Geology 166: Physics of the Earth's Interior," a course taken by nearly all first-year Seismo Lab graduate students (as undergraduates, Leon Thomsen and Bob Liebermann took this course in 1963). The class featured a demanding term project, which was often students' first introduction to serious scientific research. The projects suggested in 1985, when Duffy took this course, were the same as those in 1963, and would, in fact, still be appropriate today. Any number of these term projects eventually developed into Ph.D. thesis topics and journal publications. The lecture notes for Geology 166 formed the basis for Don's seminal 1989 textbook, Theory of the Earth ${ }^{4}$.

Don also presided over the Caltech Seismo Lab's famous twice-a-day coffee breaks, which were unique features of the Caltech experience. The coffee breaks were the locus of stimulating discussions among faculty, students, postdocs, and visitors, and covered all aspects of geophysics. They were a place to discuss the latest scientific findings, try out new ideas, and explore a wide range of scientific perspectives.

By the time Paul Asimow came to Caltech as a Ph.D. student in 1991, Don had moved firmly away from mineral physics and into contrarian geochemistry and an interest in "hotspots" and geoid anomalies. Paul later joined the Caltech faculty and inherited both Peter Wyllie's experimental petrology lab (whose capabilities he extended to all upper mantle pressures by adding a Walker-style multi-anvil device) and Tom Ahrens' shock-wave laboratory, which Paul is exploiting for numerous valuable studies of materials at high pressures and temperatures.

In 2007, Jennifer Jackson joined the Division of Geological and Planetary Sciences (GPS) faculty at Caltech and established a diamond-anvil cell (DAC) laboratory, often conducting experiments at the Advanced

${ }^{1}$ Anderson, D.L., and Bass, J.D., 1984, Mineralogy and composition of the upper mantle: Geophysical Research Letters, v. 11, no. 7, p. 637-640.

${ }^{2}$ Bass, J.D., and Anderson, D.L., 1984, Composition of the upper mantle: Geophysical tests of two petrological models: Geophysical Research Letters, v. 11, no. 3, p. 237-240.

${ }^{3}$ Duffy, T.S., and Anderson, D.L., 1989, Seismic velocities in mantle minerals and the mineralogy of the upper mantle: Journal of Geophysical Research, v. 94, p. 1895-1912.

${ }^{4}$ Anderson, D.L., 1989, Theory of the Earth: Boston, Blackwell Scientific Publications, 366 p. 
Photon Source of the Argonne National Laboratory using nuclear resonance inelastic X-ray scattering and synchrotron Mössbauer spectroscopy. Jennifer remembers one of her first interactions with Don when she was teaching a graduate mineral physics seminar.

Don recalled his work developing the Preliminary Reference Earth Model (PREM) with Adam Dziewonski in the early 1980s, when they were deciding how to account for the 220-km discontinuity. Don claimed that such a feature had to be present in any global seismic model. In December 2013, he forcefully repeated this assertion to Thorne Lay and Bob Liebermann at the fall meeting of the American Geophysical Union. Don emphasized to Jennifer that for mineral physics interpretations, he preferred higher resolution (Helmbergian) models, if available.

So you can be assured that mineral physics is alive and well at the Seismo Lab and GPS Division at Caltech. When I visited in 2009, I was struck by the contrast between the shock-wave laboratory of Paul Asimow and the DAC laboratory of Jennifer Jackson. In the latter, one could have eaten off the floor, but not so in the former.

Bob Liebermann, with help from Paul Asimow, Tom Duffy, Ed Gaffney, Jennifer Jackson, Charlie Sammis, Hartmut Spetzler, Leon Thomsen, and Jim Tyburczy

My initial impressions and memories of the Seismo Lab and Don Anderson were formed mainly in the second half of the sixties in the last century of the previous millennium.

While I have no rigorous proof, I suspect that over $90 \%$ of all Seismo-Lab scientific papers published during this era were discussed during the twice-daily coffee breaks in the dungeons, and the ideas for more than $50 \%$ originated there.

On one of those rare occasions when the conversation drifted away from science to more physical activities, someone-I don't remember who (it might have been me) — asked Don if he knew how to ski. Don's answer: "I don't know. I have never tried it, but I would probably be very good." I enjoyed that short answer from Don so much that it is imprinted on my mind. To me it reflects Don's humor, self-confidence, and general approach to life.

Let me share another short memory about the lab we built. I had come to Caltech with an unusual educational background, having been trained as an instrument/watchmaker and as an electronic technician. With Don's financial help and as his student and with the further help of Dave Newbigging, a technician who was also financed by Don, we built a gas-high-pressure laboratory in one of the garages in the upper Seismo Lab. Even though we had installed adequate safety shields, our nerves were always on edge when we charged the system. Any unexpected noise made us edgy, and that included the gentle bangs made by Charlie Richter's parking maneuvers as he used acoustics to land in his spot.

One time (I think it was the only time), Don ventured into the high-pressure lab. I was in the process of igniting a hydrogen furnace, a device that provides a highly reducing atmosphere for some fancy cleaning and brazing. For life-preserving reasons, the gas escaping from such a furnace must be burned off. A flame curtain burns off the gas as it escapes from the furnace. Igniting that curtain is simple, but the timing is critical. If it is attempted too early, with too much oxygen in the furnace, the furnace blows up - only a minor disaster. If one attempts it too late and too much hydrogen has escaped into the room, the room blows up - a major disaster. The wise igniter chooses to err on the side of too much oxygen in the furnace. Well, I was standing behind one of the concrete pillars in the lab and had a lit match at the end of an outstretched coat hanger as Don walked into the lab. The hydrogen was flowing and I could not afford to wait and probably lit the curtain just a little early. The furnace did not explode but it let us know that it wasn't done quite right. Don and I had ringing in our ears and Don, as far as I remember, never returned to the lab.

I greatly appreciate the guidance, but even more the freedom that Don provided during my graduate studies.

Hartmut Spetzler

First Publication. Once at a social event at Don and Nancy's place in Altadena, Don brought out a copy of the Rensselaer Polytechnic Institute student newspaper and showed me a piece he had written for it. It was a long, complicated joke, which I can't recall now, but it involved Cleopatra somehow. I do remember that the punch line was "You can't tell your asp from a mole in the ground!" So far as I know, that was Don's first publication. 
Normalized Derivatives. I started working for Don the summer after my sophomore year. The first job I was given was to plot an enormous number of curves that showed the partial derivatives of surface wave phase velocity with respect to various properties in a layered model. This was for a paper that I believe was (optimistically) titled "Universal Dispersion Tables" or something similar. Don explained to me once that we were actually plotting partial derivatives normalized with respect to period and layer property, and then he asked me if I had any questions about the project. I said I didn't understand how normalizing the curves as he had done necessarily made them more general. He thought about it for a few moments, and then said "Get back to work, Martin."

Martin L. Smith

I feel so fortunate to have been a grad student in the late 1960s at the Caltech Seismo Lab in the San Rafael Hills, when Clarence Allen, Don Anderson, Charles Archambeau (“Arch”), Jim Brune, and Stewart Smith were formally my teachers. Fellow students included Tom Hanks, David Hill, Bruce Julian, Lane Johnson, John McGinley, Rick O’Connell, Charlie Sammis, Hartmut Spetzler, Leon Teng, Wayne Thatcher, Frances Wu, and Max Wyss.

Typically, students and faculty would interact for hours each day, for example at coffee break in the morning and afternoon (the PA system would gently announce "coffee's ready," and students and faculty would soon gather for animated discussion in the dingy basement for a half-hour or more). And, most days, a group of students and faculty would go out to lunch together (to a place for cheap Mexican food in Eagle Rock). I remember most of the talk being about our own scientific work, and the work underway at competitor institutions, but we also enjoyed socializing together and would sometimes take off for weekends, for example, to a cabin in the San Gabriel Mountains. People clearly enjoyed their work, enjoyed talking about it, and students and teachers were treated as equal colleagues.

Charles Richter, though in retirement, was often working in the building, checking on the routine analysis of regional and teleseismic signals being recorded by the Southern California network. I still remember some of his specific suggestions on what to look for, in that era when we'd have the days' records but had no outside information on what earthquakes lay behind the signals we could see. We had many interesting visitors, including Sir Harold Jeffreys, Dan McKenzie, Keith Bullen, and Ron Oxburgh.

There was an openness about the place, and a spirit of free inquiry that enabled access to expert knowledge, while also encouraging novices to learn by asking basic questions (I didn't know the Earth had a core when I arrived; Jim Brune and Clarence Allen spent many hours teaching me to read seismograms). In retrospect, the Seismo Lab directors (Clarence Allen and Don Anderson) must have worked to bring about this supportive atmosphere. It didn't happen just by chance!

Paul G. Richards

I was a postdoc at the Seismo Lab in 1970-72, in Tom Ahrens' group (see Bob Liebermann's item on rock physics, above). This was during Don's time as lab director. Prior to my arrival, I had known of many of Don's wide-ranging contributions, but had assumed that a man with such broad interests could not be very deep in any of them. I soon learned that he had a deep understanding of all of them. For example, it would be another ten years before I understood the fundamentals, and the importance, of seismic anisotropy. Don had understood them ten years before.

On my first morning at the Lab, at about 10:00, everybody dropped what they were doing, and went from their offices to The Coffee Break. I was curious, and came along to observe this strange ritual. In the dim light of the basement, among the steam pipes, some of the world's finest geophysicists were scarfing free doughnuts and coffee. And talking geophysics. There was no talk of baseball or politics, just geophysics, with the discussion being genially directed by the Director.

It was mainly about what was being done by those individuals at the Seismo Lab, sometimes a report of a breakthrough that had happened just the day before, or it might have been an analysis of a recently published paper, or a letter from a colleague overseas. Don set the tone, with probing questions and active solicitations of the judgment of one or another of the experts present. There was little apparent organization, 
but whenever the discussion flagged, a new topic re-launched it in another direction. My head swam with the breadth and depth of these analyses.

Don recently told me that he had intentionally created this environment, where free-ranging discussion and open sharing of ideas was encouraged and expected. It was an essential expression of his leadership style. Innumerable theses and manuscripts had been inspired by these Coffee Breaks. I myself learned more geophysics in two years of Seismo Lab Coffee Breaks than I had in five years of formal instruction in graduate school. I came for the free doughnuts, but stayed for the free geophysics.

Don's office was in a large former bedroom, on the second floor of the mansion. It contained a desk and a large boardroom table, both completely covered with piles of manuscripts, plots, and other works in progress. On top of this clutter was a brass desk ornament: "A clean desk is the sign of a sick mind." Once, Don left town for a week, and his secretary seized the opportunity to organize his office. By the night before he returned, it was in perfect order, with everything in a proper place, and with the desk and table now revealed. That night, I discovered the sign (put away in a cabinet drawer), and restored it to its rightful, prominent place in the middle of the table, now empty, clean, and polished.

When Don returned the next morning, he discovered that his office was perfectly organized, and its occupant described: "A clean desk is the sign of a sick mind." He took the joke in good humor, and soon restored the table to its former state. I have observed that, whether in conscious imitation or not, most of the current faculty at the Lab have emulated this style of office organization....

Leon Thomsen

As many Seismo Lab alumni would testify, we all benefitted tremendously from the Seismo Lab coffeebreak discussions, where Don was always at the center. Occasionally, he forcefully presented his idea, but very often he was a good listener, too. Then, we later received notes and reprints on the subjects discussed, and if someone was really interested in the subject, he would pursue it in depth and eventually write an interesting paper. Many of my papers grew out of the coffee-break discussions. Don did not force others to go into a particular direction. He just sent a subtle message. He often dropped by my office for discussion. I fumbled through my big pile of papers to find the relevant materials and failed. Sometime later, I found a sign on his desk: "A clean desk is a sign of sick mind." I took it as his message to me: "Clean your desk." Unfortunately, this did not work very well for me.

Hiroo Kanamori

I first met Don in 1975 in his beloved native environment, Caltech's Seismological Laboratory, where he got his Ph.D. and worked for his entire career. Don asked me what other grad schools I was considering, and when I told him, he said, "They're all good programs. We've staffed them all."

Three years later, as I was finishing my thesis, I had a similar conversion. Fellow student (and current colleague) Emile Okal and I showed that the Indian Ocean's Ninetyeast Ridge, thought to be a dormant aseismic feature, was seismically active and showed motion between India and Australia, then thought to be a single plate. Nature's news account started "Every now and then one is brought up with a jolt as a longexpected notion is destroyed at a stroke." I showed this to Don, who smiled and said, "That's nice—it's what we expect at the Seismo Lab."

Although I never worked with Don at Caltech, I benefited from his questioning spirit. Don raised good questions about my qualifying exam proposition showing how mid-ocean ridges migrated relative to the underlying mantle, and so tapped different areas over time. Many years later, as part of challenging the mantle plume hypothesis, Don told me that it was important to bear in mind that ridges migrated over the mantle. When I reminded him that I had presented this idea to an exam he had served on, he admitted that he had forgotten that. I certainly didn't hold it against him-Don knew too much about too many things to keep track of such details.

Don contributed so much to geophysics that he was part of the environment: Many of the problems any of us considered, Don had already worked on. As Michael Wysession and I wrote our seismology text, we realized that although we knew how the quality factors describing the attenuation of $P$ and $S$ waves were 
related, we didn't know how to prove it. I asked others who didn't know either, so I dug into the question, and found that Don had derived this relation years earlier.

Don's style also influenced me and others. When Mian Liu and I were thinking of how to present our results that large earthquakes in continents had aftershocks that continued for tens or hundreds of years, we looked for an analogous paper showing that earthquake data from around the world could be described by a simple relation. We quickly chose Hiroo Kanamori's and Don's fine paper "Theoretical basis of some empirical relations in seismology"5 as our template.

Don's forte was ideas of all sorts on an incredible range of topics, based on an extraordinary range of interests and knowledge. He was not bound by prior ideas-including his own. I recall a seminar where two students summarized different papers by Don on the composition of the core, which reached opposite conclusions. Don's aggressive challenges sharpened all of our thinking, whether or not we convinced him or the reverse.

Most recently, my wife Carol and I exchanged email with Don about the Midcontinent Rift (MCR), a 3000-km-long Precambrian structure in the central U.S. Along with coworkers, we are trying to understand how the MCR combines the linear geometry of a rift with the huge — more than a million $\mathrm{km}^{3}$ — magma volume of a large igneous province. Don liked our results, which show that although the MCR had been thought to have been formed by an isolated mid-plate hotspot, it seemed instead to have formed as part of a plateboundary reorganization. However, he didn't like Rob Moucha, Tyrone Rooney, and Eric Brown's modeling results that the volume of magma was too large to result from extension alone and required a mantle thermochemical anomaly. Although Don didn't convince us for several reasons, including because most rifts don't have these huge magma volumes, his tough questions helped us.

Don's enormous legacy to geophysics includes both many now-standard results and his emphasis on the importance of challenging conventional thinking and exploring a range of ideas. He epitomized Nobel Prize winner Peter Medawar's famous advice: "I cannot give any scientist of any age better advice than this: the intensity of the conviction that a hypothesis is true has no bearing on whether it is true or not. The importance of the strength of our conviction is only to provide a proportionally strong incentive to find out if the hypothesis will stand up to critical examination."

Seth Stein

One of many memories I have of Don is related to my work at Old Faithful Geyser. During a Seismo Lab coffee break, a few days before my trip to Yellowstone where we would be placing a probe inside Old Faithful, and where my Ph.D. thesis would literally be hanging on the line, Don asked me what I expected to see. I gave my reasonably vague answer and asked Don what he expected we would observe. Don replied, "You will see nothing. The darn thing is not going to work!" We made a bet on the spot: If the instrument failed I would be teaching assistant in his class the next semester. If it worked he would provide four bottles of fine champagne.

With Don's reassuring words echoing in my head we set out for Yellowstone, and fortunately (and in no small part thanks to the good design of Dr. Brad Sturtevant of Caltech's Graduate Aeronautical Laboratories) the instrument worked, and we obtained very exciting results. I did not say much to Don upon our return. A few weeks later I saw Don walking down the street just before coffee break. He gave me a mysterious smile and walked on. A few minutes later he walked into the Benioff room carrying four bottles of high-quality champagne labeled "Anderson."

Sharon Kedar

I deeply thank Don because he saved my student career at Caltech. He was like a father for me at the Seismo Lab. I wrote my first paper in 1993 with Hiroo and Don about the Landers earthquake. I still keep his handwriting on the draft of my paper although some of it is still undecipherable. The Seismo Lab coffee break was very valuable for me. I learned real seismology from the coffee time and my thesis and papers are based on the topics discussed during the coffee breaks.

${ }^{5}$ Kanamori, H., and Anderson, D.L., 1975, Theoretical basis of some empirical relations in seismology: Bulletin of the Seismological Society of America, v. 65, p. 1073-1095. 
One day, we discussed how the equation of motion that appears in the atmospheric/ocean dynamics textbooks is related to the equation of motion in the solid Earth under gravity that can be formulated by normal-mode theory. We were confused with the Eulerian and Lagrangian treatment of the problem. Don, having observed that the coffee break discussion did not satisfy me, kindly drove me to Scripps to see Prof. Freeman Gilbert.

After the meeting with Freeman, Don brought me to a newly built, long arc-shaped bench on the Scripps campus. We experimented [with] whispering gallery waves with the concaved backrest. Around that time we were discussing the whispering gallery mechanism during coffee breaks. His voice was heard as if he was murmuring "Hi Shingo" into my ear but he was sitting quite a long way away from me. I was surprised, not only with the experiment, but also that he knew the whispering gallery bench at Scripps. With Freeman's lecture notes and much other help, I found a unified equation of motion that can describe the motion of both the ocean/atmosphere and the solid Earth. This eventually resulted in my thesis.

Shingo Watada

Seismo Lab coffee was an important part of life in the Seismo Lab, at 9:30 a.m. and 2:30 p.m., and Don presided over it most days. When I was a student, one of the first digital seismometers was installed in Pasadena, and Hiroo Kanamori often brought new things that had not been seen before to coffee and we would all discuss them. One mysterious pulse, which was called phase $X$, puzzled us for several days. It did not look like an earthquake and was distinctive in that it was a single pulse and emanated from the Los Angeles basin. With some detective work, Hiroo figured out that it was the sonic boom from the Space Shuttle reentering the atmosphere exciting vibrations of the large buildings downtown. Don immediately suggested naming it the "Downtown Los Angeles" phase. Hiroo chuckled and said, “Aaahhhhh... no." End of conversation.

Scott D. King 
Downloaded from specialpapers.gsapubs.org on February 4, 2016 


\section{Geological Society of America Special Papers}

\section{Don L. Anderson and the Caltech Seismo Lab}

Geological Society of America Special Papers 2015;514; ix-xix doi:10.1130/2015.2514(ix)

\section{E-mail alerting services click www.gsapubs.org/cgi/alerts to receive free e-mail alerts when new articles cite this article \\ Subscribe click www.gsapubs.org/subscriptions to subscribe to Geological Society of America Special Papers \\ Permission request click www.geosociety.org/pubs/copyrt.htm\#gsa to contact GSA.}

Copyright not claimed on content prepared wholly by U.S. government employees within scope of their employment. Individual scientists are hereby granted permission, without fees or further requests to GSA, to use a single figure, a single table, and/or a brief paragraph of text in subsequent works and to make unlimited copies of items in GSA's journals for noncommercial use in classrooms to further education and science. This file may not be posted to any Web site, but authors may post the abstracts only of their articles on their own or their organization's Web site providing the posting includes a reference to the article's full citation. GSA provides this and other forums for the presentation of diverse opinions and positions by scientists worldwide, regardless of their race, citizenship, gender, religion, or political viewpoint. Opinions presented in this publication do not reflect official positions of the Society.

Notes

(C) 2015 Geological Society of America

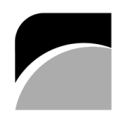

THE

GEOLOGICAL

SOCIETY

OF AMERICA 